\title{
Divergência genética de genótipos de feijão-de-corda quanto à resistência ao pulgão-preto
}

\author{
Jefté Ferreira da Silva(1), Cândida Hermínia Campos de Magalhães Bertini(1), Ervino Bleicher ${ }^{(1)}$ \\ e João Gutemberg Leite Moraes ${ }^{(1)}$
}

\begin{abstract}
(1)Universidade Federal do Ceará, Avenida Mister Hull, s/non, Pici, CEP 60455-760 Fortaleza, CE. E-mail: jefteferreira@gmail.com, candida@ufc.br, ervino@ufc.br, gutemberg2@gmail.com
\end{abstract}

Resumo - $\mathrm{O}$ objetivo deste trabalho foi avaliar a divergência genética entre genótipos de feijão-de-corda quanto à resistência ao pulgão-preto (Aphis craccivora) e identificar as melhores combinações entre genótipos resistentes. Utilizou-se o delineamento de blocos ao acaso, com 51 tratamentos, representados pelos genótipos, e quatro repetições. As plantas foram infestadas 15 dias após a semeadura, com cinco fêmeas adultas. Avaliaram-se o número de adultos e de ninfas, respectivamente aos dois e quatro dias após a infestação, e a relação entre eles. O índice de soma de postos de Mulamba \& Mock, as distâncias generalizadas de Mahalanobis e o método de otimização de Tocher foram utilizados para avaliar a divergência genética entre os genótipos. As maiores divergências foram observadas entre os genótipos BRS Guariba e Sete Semanas, e entre TVu 410 e Sete Semanas, enquanto BRS Guariba e TVu 410 foram os mais similares. Os genótipos BRS Guariba, TVu 410, BRS Paraguaçu, TVu 36, Sempre Verde, TVu $408 \mathrm{P}_{2}$, Setentão e Epace 10 apresentam resistência ao pulgão. Os cruzamentos entre Setentão e BRS Guariba, TVu 410, BRS Paraguaçu, TVu 36, TVu $408 \mathrm{P}_{2}$ e entre Epace 10 e Sempre Verde, BRS Guariba e TVu 410 são promissores para novas combinações genéticas em programas de melhoramento com vistas à resistência ao pulgão.

Termos para indexação: Aphis craccivora, Vigna unguiculata, análise multivariada, resistência genética.

\section{Genetic divergence of cowpea genotypes for resistance to black aphid}

\begin{abstract}
The objective of this work was to evaluate the genetic divergence among cowpea genotypes as to resistance to black aphid (Aphis craccivora), and to identify the best combinations between resistant genotypes. The experimental design was a randomized complete blocks with 51 treatments, represented by genotypes, and four replicates. Plants were infested 15 days after sowing, with five female adults. The number of adults and nymphs, at two and four days after infestation, respectively, and the relationship between them were evaluated. Mulamba \& Mock's sum of ranks index, Mahalanobis' generalized distances, and Tocher's optimization method were used to assess the genetic distance among genotypes. The largest differences were observed between the genotypes BRS Guariba and Sete Semanas, and between TVu 410 and Sete Semanas, whereas BRS Guariba and TVu 410 were the most similar. The genotypes BRS Guariba, TVu 410, BRS Paraguaçu, TVu 36, Sempre Verde, TVu $408 \mathrm{P}_{2}$, Setentão, and Epace 10 show resistance to black aphid. Crossings between Setentão and BRS Guariba, TVu 410, BRS Paraguaçu, TVu 36, TVu $408 \mathrm{P}_{2}$, and between Epace 10 and Sempre Verde, BRS Guariba and TVu 410 are promising for new genetic combinations in breeding programs to improve resistance to black aphid.
\end{abstract}

Index terms: Aphis craccivora, Vigna unguiculata, multivariate analysis, genetic resistance.

\section{Introdução}

O pulgão-preto do feijoeiro [Aphis craccivora Koch, 1854 (Hemiptera: Aphididae)] é uma praga cosmopolita que se alimenta de várias espécies vegetais, especialmente Fabaceas (Rakhshani et al., 2005). Adultos e ninfas do pulgão causam danos econômicos significantes ao feijão-de-corda, tanto direta quanto indiretamente. Os danos diretos são causados pela sucção de seiva, principalmente de ramos novos, flores, vagens e folhas, o que causa o definhamento e até mesmo a morte da planta. Já os indiretos, ocorrem por meio da transmissão de vírus como, por exemplo, o Cowpea aphid borne mosaic virus (CABMV) e o Cucumber mosaic virus (CMV) (Obopile, 2006).

Para reduzir ou até mesmo evitar danos provocados por esta praga, tem-se adotado diferentes métodos de controle, entre os quais se destacam o químico, o

Pesq. agropec. bras., Brasília, v.47, n.7, p.948-954, jul. 2012 
biológico (Rakhshani et al., 2005) e o uso de plantas resistentes (Hall et al., 2003; Obopile \& Ositile, 2010). O entendimento da relação planta/inseto é importante para o uso de plantas resistentes. Entretanto, pouco se sabe sobre o efeito direto do pulgão-preto sobre as cultivares de feijão-de-corda existentes, o que torna necessária a avaliação de germoplasma frente à população do afídeo no Brasil (Moraes \& Bleicher, 2007).

Em experimentos conduzidos no Nordeste brasileiro, em casa de vegetação, as cultivares Epace 10 e Patativa foram as menos preferidas pelo pulgão, quando comparadas às cultivares Epace 11, Pitiúba e Pingo de Ouro (Moraes \& Bleicher, 2007). Em outro experimento, esses autores concluíram que as cultivares BR-12 Canindé, BR-17 Gurguéia, BR-14 Mulato e BR-10 Piauí não diferiram da cultivar suscetível Pitiúba, recomendada como padrão de suscetibilidade. Silva \& Bleicher (2010) avaliaram 20 genótipos de feijão-de-corda, em experimento com e sem chance de escolha para o pulgão, e verificaram possível resistência do tipo antibiose. Em estudos conduzidos em Botswana, África, a variedade IT835-720-20 apresentou alta resistência ao pulgão-preto do feijoeiro quando comparada às variedades Blackeye, B005-C, INIA-37 e TVx 3671-14C-OID. O aumento no período pré-reprodutivo e a redução no desempenho reprodutivo da praga naquela variedade são indicativos de antibiose como forma de resistência (Obopile \& Ositile, 2010).

Para o melhoramento do feijão-de-corda com vistas à resistência ao pulgão-preto, o estudo da divergência de populações é de grande proveito para identificação de progenitores divergentes e, consequentemente, combinações híbridas de maior efeito heterótico e maior heterozigose, o que aumenta a possibilidade de obtenção de genótipos superiores nas gerações segregantes (Cruz \& Regazzi, 2001; Oliveira et al., 2003). Vários ensaios, com diferentes espécies, têm sido realizados para examinar a divergência genética relacionada à qualidade e às características de produção (Oliveira et al., 2003; Ribeiro et al., 2005; Dias et al., 2009). Entretanto, poucos são os estudos de divergência para identificação de fontes de resistência a insetos. Por exemplo, Suinaga et al. (2003) avaliaram dez genótipos de Lycopersicon spp. quanto à resistência à traça-do-tomateiro [Tuta absoluta Meyrick, 1917 (Lepidoptera: Gelechiidae)] por meio do emprego de análises multivariadas. Já Souza et al. (2009), analisaram a divergência genética de 16 cultivares de arroz quanto à resistência ao percevejo-do-colmo [Tibraca limbativentris Stål (Hemiptera: Pentatomidae)].

O objetivo deste trabalho foi avaliar a divergência genética entre genótipos de feijão-de-corda quanto à resistência ao pulgão-preto e identificar as melhores combinações entre genótipos resistentes.

\section{Material e Métodos}

O experimento foi conduzido em casa de vegetação, no Campus do Pici, da Universidade Federal do Ceará, no Município de Fortaleza ( $3^{\circ} 44^{\prime} 48^{\prime \prime} \mathrm{S}$ e $\left.38^{\circ} 34^{\prime} 30^{\prime \prime} \mathrm{W}\right)$, no período de 15/8/2009 a 9/10/2009. As temperaturas máximas e mínimas médias no local foram de $31,71^{\circ} \mathrm{C} \pm 0,63$ e $25,32^{\circ} \mathrm{C} \pm 0,67$, respectivamente. A umidade máxima média foi de $77,33 \% \pm 2,24$ e a mínima média foi de $57,11 \% \pm 4,65$.

As sementes dos genótipos de feijão-de-corda [Vigna unguiculata (L.) Walp.] avaliados foram plantadas em vasos descartáveis de poliestireno, de $300 \mathrm{~mL}$, contendo substrato constituído de areia peneirada, húmus de minhoca e vermiculita, na proporção de 6:3:1. Foram semeadas duas sementes por vaso e, posteriormente, feito o desbaste, tendo-se deixado apenas uma planta. Cada vaso foi identificado com um número de campo (NC), para identificação correta do genótipo e para facilitar o processo de avaliação. Utilizou-se o delineamento de blocos ao acaso, com 51 tratamentos (genótipos) e quatro repetições. Os genótipos de número 1 a 27 são plantas de porte ereto e ciclo curto, utilizadas em estudos de divergência genética quanto a características de produção (Dias et al., 2009), e fazem parte do Banco Ativo de Germoplasma da Universidade Federal do Ceará (Tabela 1). Os genótipos de número 28 a 36 e de 46 a 50 são cultivares utilizadas localmente no Estado do Ceará. Os genótipos de número 37 a 41 são cultivares desenvolvidas pela Embrapa, e os de número 42 a 45 são provenientes do banco de germoplasma do International Institute of Tropical Agriculture (IITA). A cultivar Vita 7 é amplamente utilizada em estudos de resistência.

Ao se considerar o tempo necessário para as avaliações e o elevado número de genótipos, as semeaduras foram escalonadas no tempo, tendose formado quatro blocos que foram conduzidos 
individualmente. Cada parcela, ou unidade experimental, consistiu-se de uma planta por vaso. Os blocos foram arranjados em gaiolas de 1,0 m de largura por $1,0 \mathrm{~m}$ de comprimento e $0,50 \mathrm{~m}$ de altura para evitar a entrada de outros insetos e inimigos naturais. Neste experimento, os pulgões tinham a oportunidade de se locomover entre os diversos genótipos avaliados, o que caracteriza experimento com chance de escolha, no qual é avaliada a preferência dos insetos pela planta (Painter, 1968).

As plantas foram infestadas, após 15 dias da semeadura, com cinco pulgões $A$. craccivora, fêmeas, adultas, ápteras e de coloração preta brilhante, provenientes da criação mantida na própria universidade. Após dois dias da infestação, foram contados e retirados os adultos que estavam nas plantas e, depois de quatro dias da infestação, foi mensurado o número de ninfas presentes em cada genótipo. A partir destes dados, foi obtida a relação do número de ninfas

Tabela 1. Genótipos de feijão-de-corda (Vigna unguiculata) avaliados no estudo de resistência ao pulgão-preto (Aphis craccivora).

\begin{tabular}{|c|c|c|c|}
\hline $\begin{array}{l}\text { Número de } \\
\text { campo }\end{array}$ & Genótipo & $\begin{array}{l}\text { Número de } \\
\text { campo }\end{array}$ & Genótipo \\
\hline 1 & Milagroso & 27 & MNC03-720-11 \\
\hline 2 & Rouxinho-1 & 28 & Sempre verde \\
\hline 3 & 58.185 & 29 & Setentão \\
\hline 4 & Rouxinho-2 & 30 & Epace 10 \\
\hline 5 & Burgandy Cowpea & 31 & Pitiúba \\
\hline 6 & 7917-Dixie hee & 32 & Aparecido UFC \\
\hline 7 & Purple KNUCKIE Hull-55 & 33 & Frade Preto \\
\hline 8 & $\mathrm{CNCx} 251-60 \mathrm{E}$ & 34 & Paulistinha \\
\hline 9 & ER-7 & 35 & Inhunmã \\
\hline 10 & CNCx 251-11E & 36 & Lisão CE \\
\hline 11 & CNCx 251-76E & 37 & BRS Gurguéia \\
\hline 12 & TVx 4662-07F & 38 & BRS Marataoã \\
\hline 13 & BR9 - Longá & 39 & BRS Guariba \\
\hline 14 & $\mathrm{CB}-3$ & 40 & BRS Paraguaçu \\
\hline 15 & $\mathrm{CB}-27$ & 41 & BRS Rouxinol \\
\hline 16 & IT $870-611-3$ & 42 & TVu 36 \\
\hline 17 & IT82D - 60 & 43 & TVu 410 \\
\hline 18 & AU94-418-07-01 & 44 & TVu 1037 \\
\hline 19 & UCR-95-701 & 45 & TVu $408 \mathrm{P}_{2}$ \\
\hline 20 & IT87D-611-3 & 46 & Maranhão \\
\hline 21 & MNC 03-720C-11 & 47 & Chumbinho \\
\hline 22 & MNC-00-5190-1-1-5 & 48 & Jatobá \\
\hline 23 & $\mathrm{MNC}-00-553-\mathrm{D}-81-2-3$ & 49 & Sete semanas \\
\hline 24 & MNC01-627D-65-1 & 50 & Manteiguinha \\
\hline 25 & IT91K-118-2 & 51 & Vita 7 \\
\hline 26 & IT93-10-93 & - & - \\
\hline
\end{tabular}

com o número inicial de adultos (NIA) dispostos em cada planta (relação ninfas/NIA). As seguintes variáveis foram utilizadas na avaliação da resistência desses genótipos ao pulgão-preto: número de adultos, número de ninfas e relação ninfas/NIA.

Para a análise estatística, os dados das variáveis foram transformados em $(\mathrm{x}+0,5)^{0,5}$ e submetidos à análise de variância com uso do programa Genes (Cruz, 2006). Foram associados o índice de classificação soma de postos, proposto por Mulamba \& Mock (1978), e o teste de Scott-Knott (Scott \& Knott, 1974). Para isso, conforme Silva \& Bleicher (2010), o índice de soma de postos de Mulamba \& Mock (1978) foi aplicado a cada uma das três variáveis dentro de cada repetição, a partir dos dados da parcela. Assim, o índice passou a ser considerado como novo caráter, tendo sido testado estatisticamente por meio da análise de variância, cujas médias foram comparadas pelo teste de Scott-Knott, a 5\% de probabilidade. A distância generalizada de Mahalanobis $\left(\mathrm{D}^{2}\right)$ foi utilizada como medida de dissimilaridade genética, e a técnica utilizada para o agrupamento dos genótipos foi o método de otimização de Tocher. Também foram estimadas a maior e a menor distância entre cada cultivar e as distâncias médias intergrupos correspondentes aos grupos formados.

\section{Resultados e Discussão}

Observou-se, pela análise de variância, diferença significativa entre os 51 genótipos, para as variáveis número de adultos, número de ninfas e relação ninfas/ NIA $(p<0,01)$. Na comparação das médias, houve divisão dos genótipos em três grupos, denominados de resistente, moderadamente resistente e suscetível (Tabela 2).

Os genótipos BRSGuariba, TVu410, BRSParaguaçu, TVu 36, Sempre Verde, TVu 408 P 2 , Setentão e Epace 10 foram os mais resistentes ao pulgão-preto do feijoeiro e são indicados para programas de melhoramento com a finalidade de promover resistência a esta praga. Neste grupo, destaca-se o BRS Guariba, que apresentou a melhor classificação nas três variáveis (Tabela 2). $\mathrm{Na}$ literatura, há relatos da resistência dos genótipos TVu $408 \mathrm{P}_{2}$, TVu 410 e TVu 36 (Silva \& Bleicher, 2010), e da antibiose como tipo de resistência para $\mathrm{TVu} 408 \mathrm{P}_{2}$ e TVu 410 (Singh, 1977). O genótipo Epace 10 foi descrito como resistente em experimento 
Tabela 2. Classificação dos 51 genótipos de feijão-de-corda (Vigna unguiculata) quanto à preferência do pulgão-preto (Aphis craccivora), ao levar-se em consideração as variáveis número de adultos, número de ninfas e relação ninfas/número inicial de adultos.

\begin{tabular}{|c|c|c|c|c|c|c|c|c|}
\hline Número de campo & Genótipo & Adultos & $\mathrm{Cl}^{(1)}$ & Ninfas & $\mathrm{Cl}$. & Relação & $\mathrm{Cl}$. & Soma de postos ${ }^{(2)}$ \\
\hline 39 & BRS Guariba & 0,00 & 1 & 0,50 & 1 & 0,10 & 1 & $3 \mathrm{a}$ \\
\hline 43 & TVu 410 & 0,00 & 3 & 0,50 & 2 & 0,10 & 2 & $7 \mathrm{a}$ \\
\hline 40 & BRS Paraguaçu & 0,00 & 2 & 0,75 & 3 & 0,15 & 3 & $8 \mathrm{a}$ \\
\hline 42 & TVu 36 & 0,25 & 6 & 0,75 & 4 & 0,15 & 4 & $14 \mathrm{a}$ \\
\hline 28 & Sempre verde & 0,25 & 4 & 4,25 & 6 & 0,85 & 6 & $16 \mathrm{a}$ \\
\hline 45 & $\mathrm{TVu} 408 \mathrm{P}_{2}$ & 0,50 & 7 & 2,75 & 5 & 0,55 & 5 & $17 \mathrm{a}$ \\
\hline 29 & Setentão & 0,25 & 5 & 6,00 & 8 & 1,20 & 8 & $21 \mathrm{a}$ \\
\hline 30 & Epace 10 & 1,50 & 10 & 5,75 & 7 & 1,15 & 7 & $24 \mathrm{a}$ \\
\hline 24 & MNC01-627D-65-1 & 1,25 & 8 & 16,00 & 9 & 3,20 & 9 & $26 \mathrm{~b}$ \\
\hline 44 & TVu 1037 & 1,25 & 9 & 23,00 & 11 & 4,60 & 11 & $31 \mathrm{~b}$ \\
\hline 22 & MNC-00-5190-1-1-5 & 2,25 & 14 & 18,00 & 10 & 3,60 & 10 & $34 \mathrm{~b}$ \\
\hline 21 & MNC 03-720C-11 & 2,00 & 12 & 29,25 & 12 & 5,85 & 12 & $36 \mathrm{~b}$ \\
\hline 50 & Manteiguinha & 1,50 & 11 & 30,50 & 13 & 6,10 & 13 & $37 \mathrm{~b}$ \\
\hline 36 & Lisão CE & 2,00 & 13 & 35,00 & 14 & 7,00 & 14 & $41 \mathrm{~b}$ \\
\hline 7 & Purple KNUCKIE Hull-55 & 2,50 & 16 & 38,75 & 15 & 7,75 & 15 & $46 b$ \\
\hline 27 & MNC03-720-11 & 2,25 & 15 & 40,50 & 17 & 8,10 & 17 & $49 \mathrm{~b}$ \\
\hline 16 & IT 870-611-3 & 3,50 & 21 & 40,25 & 16 & 8,05 & 16 & $53 \mathrm{c}$ \\
\hline 13 & BR9 - Longá & 3,25 & 20 & 46,75 & 18 & 9,35 & 18 & $56 \mathrm{c}$ \\
\hline 33 & Frade Preto & 2,50 & 17 & 47,75 & 20 & 9,55 & 20 & $57 \mathrm{c}$ \\
\hline 12 & TVx 4662-07F & 2,75 & 18 & 53,50 & 21 & 10,70 & 21 & $60 \mathrm{c}$ \\
\hline 31 & Pitiúba & 3,00 & 19 & 54,25 & 23 & 10,85 & 23 & $65 \mathrm{c}$ \\
\hline 41 & BRS Rouxinol & 3,50 & 22 & 54,00 & 22 & 10,80 & 22 & $66 \mathrm{c}$ \\
\hline 38 & BRS Marataoã & 4,00 & 29 & 47,25 & 19 & 9,45 & 19 & $67 \mathrm{c}$ \\
\hline 1 & Milagroso & 4,00 & 24 & 55,25 & 24 & 11,05 & 24 & $72 \mathrm{c}$ \\
\hline 32 & Aparecido UFC & 4,00 & 27 & 60,25 & 27 & 12,05 & 27 & $81 \mathrm{c}$ \\
\hline 35 & Inhunmã & 4,50 & 37 & 59,50 & 25 & 11,90 & 25 & $87 \mathrm{c}$ \\
\hline 48 & Jatobá & 4,00 & 30 & 62,50 & 29 & 12,50 & 29 & $88 \mathrm{c}$ \\
\hline 5 & Burgandy Cowpea & 4,00 & 26 & 65,00 & 32 & 13,00 & 32 & $90 \mathrm{c}$ \\
\hline 8 & CNCx 251-60E & 4,25 & 31 & 64,25 & 30 & 12,85 & 30 & $91 \mathrm{c}$ \\
\hline 9 & ER-7 & 3,75 & 23 & 68,75 & 34 & 13,75 & 34 & $91 \mathrm{c}$ \\
\hline 47 & Chumbinho & 4,50 & 39 & 60,00 & 26 & 12,00 & 26 & $91 \mathrm{c}$ \\
\hline 11 & CNCx $251-76 \mathrm{E}$ & 4,25 & 32 & 64,50 & 31 & 12,90 & 31 & $94 \mathrm{c}$ \\
\hline 51 & Vita 7 & 4,75 & 43 & 62,00 & 28 & 12,40 & 28 & $99 \mathrm{c}$ \\
\hline 25 & IT91K-118-2 & 4,50 & 36 & 67,00 & 33 & 13,40 & 33 & $102 \mathrm{c}$ \\
\hline 3 & 58.185 & 4,00 & 25 & 77,25 & 43 & 15,45 & 43 & $111 \mathrm{c}$ \\
\hline 20 & IT87D-611-3 & 4,50 & 35 & 73,00 & 38 & 14,60 & 38 & $111 \mathrm{c}$ \\
\hline 4 & Rouxinho-2 & 4,75 & 40 & 71,75 & 37 & 14,35 & 37 & $114 \mathrm{c}$ \\
\hline 15 & $\mathrm{CB}-27$ & 5,25 & 47 & 70,50 & 36 & 14,10 & 36 & $119 \mathrm{c}$ \\
\hline 34 & Paulistinha & 4,00 & 28 & 79,75 & 46 & 15,95 & 46 & $120 \mathrm{c}$ \\
\hline 26 & IT93-10-93 & 5,75 & 51 & 69,50 & 35 & 13,90 & 35 & $121 \mathrm{c}$ \\
\hline 19 & UCR-95-701 & 4,50 & 34 & 79,00 & 44 & 15,80 & 44 & $122 \mathrm{c}$ \\
\hline 17 & IT82D - 60 & 4,75 & 41 & 75,50 & 41 & 15,10 & 41 & $123 \mathrm{c}$ \\
\hline 14 & $\mathrm{CB}-3$ & 5,00 & 45 & 74,00 & 40 & 14,80 & 40 & $125 \mathrm{c}$ \\
\hline 49 & Sete semanas & 5,50 & 49 & 73,50 & 39 & 14,70 & 39 & $127 \mathrm{c}$ \\
\hline 18 & AU94-418-07-01 & 5,00 & 46 & 76,00 & 42 & 15,20 & 42 & $130 \mathrm{c}$ \\
\hline 37 & BRS Gurguéia & 4,75 & 42 & 79,50 & 45 & 15,90 & 45 & $132 \mathrm{c}$ \\
\hline 2 & Rouxinho-1 & 4,50 & 33 & 91,50 & 50 & 18,30 & 50 & $133 \mathrm{c}$ \\
\hline 46 & Maranhão & 4,50 & 38 & 81,25 & 48 & 16,25 & 48 & $134 \mathrm{c}$ \\
\hline 10 & CNCx 251-11E & 5,00 & 44 & 80,50 & 47 & 16,10 & 47 & $138 \mathrm{c}$ \\
\hline 6 & 7917-Dixie hee & 5,50 & 48 & 83,25 & 49 & 16,65 & 49 & $146 \mathrm{c}$ \\
\hline 23 & MNC-00-553-D-81-2-3 & 5,75 & 50 & 94,50 & 51 & 18,90 & 51 & $152 \mathrm{c}$ \\
\hline
\end{tabular}

${ }^{(1)}$ Cl., Classificação quanto à variável observada. (2)Índices de soma de postos de Mulamba \& Mock (1978), seguidos de letras iguais, nas colunas, não diferem pelo teste de Scott-Knott, a 5\% de probabilidade. Dados transformados em $(\mathrm{x}+0,5)^{1 / 2}$. 
Tabela 3. Medidas de dissimilaridade genética $\left(D^{2}\right)$ entre os 51 genótipos de feijão-de-corda (Vigna unguiculata), avaliados quanto à resistência ao pulgão-preto (Aphis craccivora).

\begin{tabular}{|c|c|c|c|c|c|}
\hline \multirow{2}{*}{$\begin{array}{l}\text { Número } \\
\text { de campo }\end{array}$} & \multirow[t]{2}{*}{ Genótipos } & \multicolumn{4}{|c|}{ Distância $\mathrm{D}^{2}$ entre genótipos } \\
\hline & & \multicolumn{2}{|c|}{ Menores } & \multicolumn{2}{|c|}{ Maiores } \\
\hline 1 & Milagroso & 0,142 & 32 & 44,313 & 39 \\
\hline 2 & Rouxinho-1 & 0,347 & 34 & 46,051 & 39 \\
\hline 3 & 58,185 & 0,161 & 19 & 44,043 & 39 \\
\hline 4 & Rouxinho-2 & 0,044 & 17 & 45,105 & 39 \\
\hline 5 & Burgandy Cowpea & 0,048 & 48 & 43,804 & 39 \\
\hline 6 & 7917-Dixie hee & 0,122 & 18 & 48,173 & 39 \\
\hline 7 & Purple KNUCKIE Hull-55 & 0,196 & 13 & 36,428 & 39 \\
\hline 8 & $\mathrm{CNCx} 251-60 \mathrm{E}$ & 0,019 & 48 & 46,583 & 39 \\
\hline 9 & ER-7 & 0,176 & 5 & 45,359 & 39 \\
\hline 10 & CNCx 251-11E & 0,058 & 17 & 47,423 & 39 \\
\hline 11 & CNCx 251-76E & 0,055 & 25 & 44,162 & 39 \\
\hline 12 & TVx 4662-07F & 0,085 & 33 & 43,682 & 39 \\
\hline 13 & BR9 - Longá & 0,196 & 7 & 39,893 & 39 \\
\hline 14 & $\mathrm{CB}-3$ & 0,050 & 18 & 42,309 & 39 \\
\hline 15 & $\mathrm{CB}-27$ & 0,128 & 49 & 44,657 & 39 \\
\hline 16 & IT $870-611-3$ & 0,850 & 38 & 32,064 & 39 \\
\hline 17 & IT82D - 60 & 0,044 & 4 & 45,079 & 39 \\
\hline 18 & AU94-418-07-01 & 0,050 & 14 & 45,256 & 39 \\
\hline 19 & UCR-95-701 & 0,045 & 37 & 47,455 & 39 \\
\hline 20 & IT87D-611-3 & 0,063 & 17 & 45,233 & 39 \\
\hline 21 & MNC 03-720C-11 & 0,289 & 7 & 32,039 & 39 \\
\hline 22 & MNC-00-5190-1-1-5 & 1,811 & 16 & 20,921 & 39 \\
\hline 23 & MNC-00-553-D-81-2-3 & 1,024 & 46 & 42,545 & 39 \\
\hline 24 & MNC01-627D-65-1 & 0,700 & 44 & 16,741 & 23 \\
\hline 25 & IT91K-118-2 & 0,051 & 4 & 43,916 & 39 \\
\hline 26 & IT93-10-93 & 0,134 & 15 & 47,593 & 39 \\
\hline 27 & MNC 03-720-11 & 0,115 & 36 & 36,082 & 39 \\
\hline 28 & Sempre verde & 0,459 & 45 & 34,164 & 49 \\
\hline 29 & Setentão & 0,790 & 44 & 26,926 & 6 \\
\hline 30 & Epace 10 & 1,552 & 45 & 29,290 & 2 \\
\hline 31 & Pitiúba & 0,615 & 27 & 34,193 & 39 \\
\hline 32 & Aparecido UFC & 0,057 & 48 & 47,044 & 39 \\
\hline 33 & Frade Preto & 0,085 & 12 & 43,684 & 39 \\
\hline 34 & Paulistinha & 0,140 & 46 & 39,546 & 39 \\
\hline 35 & Inhunmã & 0,002 & 47 & 44,602 & 39 \\
\hline 36 & Lisão CE & 0,115 & 27 & 37,546 & 39 \\
\hline 37 & BRS Gurguéia & 0,045 & 19 & 46,399 & 39 \\
\hline 38 & BRS Marataoã & 0,276 & 1 & 42,645 & 39 \\
\hline 39 & BRS Guariba & 0,000 & 43 & 48,945 & 49 \\
\hline 40 & BRS Paraguaçu & 0,003 & 39 & 48,431 & 49 \\
\hline 41 & BRS Rouxinol & 1,705 & 31 & 24,466 & 39 \\
\hline 42 & TVu 36 & 0,223 & 39 & 46,265 & 49 \\
\hline 43 & TVu 410 & 0,000 & 39 & 48,945 & 49 \\
\hline 44 & TVu 1037 & 0,700 & 24 & 19,727 & 26 \\
\hline 45 & $\mathrm{TVu} 408 \mathrm{P}_{2}$ & 0,459 & 28 & 34,534 & 6 \\
\hline 46 & Maranhão & 0,140 & 34 & 40,462 & 39 \\
\hline 47 & Chumbinho & 0,002 & 35 & 44,379 & 39 \\
\hline 48 & Jatobá & 0,019 & 8 & 45,022 & 39 \\
\hline 49 & Sete semanas & 0,128 & 15 & 48,945 & 39 \\
\hline 50 & Manteiguinha & 0,747 & 36 & 30,505 & 39 \\
\hline 51 & Vita 7 & 0,040 & 35 & 46,997 & 39 \\
\hline \multicolumn{2}{|c|}{ Menor distância geral } & 0,0 & 39 e 43 & - & - \\
\hline \multicolumn{2}{|c|}{ Maior distância geral } & - & - & 48,945 & $\begin{array}{l}39 \text { e } 49 \\
43 \text { e } 49\end{array}$ \\
\hline
\end{tabular}

em casa de vegetação, também em análise de preferência (Moraes \& Bleicher, 2007).

A cultivar Epace 10 apresentou resistência moderada em experimento anterior, enquanto a cultivar TVu 1037 apresentou alta resistência (Silva \& Bleicher, 2010), como também observado por Ofuya (1997). Entretanto, no presente trabalho, Epace 10 foi incluída no grupo de genótipos resistentes e $\mathrm{TVu} 1037$ no grupo de genótipos tidos como de resistência moderada. Isso pode ser atribuído ao fato de o resultado da avaliação em ensaios de estudo da resistência não ser absoluto, ou seja, a comparação com outras cultivares mais e menos resistentes altera a ordem de classificação. Outra possível explicação seria que as condições ambientais durante o experimento podem ter influenciado a expressão da resistência.

O grupo suscetível foi o maior observado, com 35 dos genótipos avaliados (cerca de 69\%). Portanto, é alta a quantidade de cultivares que são prejudicadas pelo ataque do pulgão. Muitas das cultivares suscetíveis são de uso comercial ou local, o que pode causar prejuízos aos produtores que as utilizam. Desses genótipos, BRS Gurguéia, Pitiúba, Vita 7, Sete Semanas, Maranhão e Inhumã foram relatados como suscetíveis (Moraes \& Bleicher, 2007; Silva \& Bleicher, 2010). O genótipo Manteiguinha apresentou resistência moderada, conforme observado em outros experimentos (Silva \& Bleicher, 2010).

As medidas de dissimilaridade genética estimadas pela distância generalizada de Mahalanobis $\left(\mathrm{D}^{2}\right)$ entre os genótipos avaliados (Tabela 3) apontaram BRS Guariba (39) e Sete Semanas (49) e TVu 410 (43) e Sete Semanas $(49)\left(D^{2}=48,945\right)$ como as combinações mais dissimilares, e BRS Guariba (39) e TVu 410 (43) como a mais similar. Observou-se que $80,4 \%$ das maiores distâncias $\mathrm{D}^{2}$ ocorreram quando os genótipos foram combinados com BRS Guariba (39). Os altos valores de $\mathrm{D}^{2}$, principalmente quando combinados com BRS Guariba (39), mostram ampla variabilidade genética quanto à resistência ao pulgão-preto do feijoeiro nos genótipos avaliados. Estes resultados são indicativos da existência de variabilidade genética nos genótipos em estudo.

Os genótipos mais dissimilares são mais indicados para a combinação híbrida, nas etapas iniciais do programa de melhoramento. Assim, espera-se que, em razão da divergência genética, seja possível maior recombinação e obtenção de maior efeito heterótico, 
com maiores chances de ocorrência de combinações gênicas favoráveis (Oliveira et al., 2003). Outro critério a ser considerado na escolha de genitores para cruzamentos é se estes apresentam bom rendimento na característica que se deseja melhorar (Suinaga et al., 2003). Desse modo, as combinações híbridas recomendadas para uso em programas de melhoramento devem envolver, na medida do possível, genitores dissimilares e com desempenho superior (Abreu et al., 1999). Portanto, os cruzamentos entre os genótipos Setentão e BRS Guariba $\left(\mathrm{D}^{2}=6,5776\right), \mathrm{TVu} 410\left(\mathrm{D}^{2}=6,5776\right)$, BRS Paraguaçu $\left(\mathrm{D}^{2}=6,3176\right), \mathrm{TVu} 36\left(\mathrm{D}^{2}=6,8378\right), \mathrm{TVu} 408 \mathrm{P}_{2}$ $\left(\mathrm{D}^{2}=2,9920\right)$ e entre Epace 10 e Sempre Verde $\left(\mathrm{D}^{2}=3,0596\right)$, BRS Guariba $\left(\mathrm{D}^{2}=5,8214\right)$ e TVu 410 $\left(\mathrm{D}^{2}=5,8214\right)$ são mais indicados, uma vez que as maiores divergências foram observadas entre estes genótipos resistentes.

Ao se utilizar o método de otimização de Tocher, baseado na dissimilaridade obtida por meio da distância de Mahalanobis, foi possível observar distribuição dos genótipos avaliados em oito grupos distintos, com grande divergência entre eles (Tabela 4). Os grupos formados por este método se assemelharam aos obtidos pela associação da classificação de Mulamba \& Mock com o teste de Scott-Knott. O grupo 1, obtido pelo método de Tocher, contém seis dos oito genótipos considerados resistentes pelo método anterior [BRS Guariba (39), TVu 410 (43), BRS Paraguaçu (40), TVu 36 (42), Sempre Verde (28) e TVu $408 \mathrm{P}_{2}$ (45)]. Os outros genótipos resistentes, Epace 10 (30) e Setentão (29), foram incluídos no grupo 8 e 4, respectivamente. $O$ grupo 2 conteve quase todos os genótipos (27 dos 35 listados na Tabela 4) classificados como suscetíveis. Os outros ficaram distribuídos nos grupos 3, 5, 6 e 7 .

Quanto à distância entre os grupos, as maiores médias foram observadas entre os grupos 1 e 2 $(39,933), 1$ e $3(32,421)$, e 1 e $5(39,842)$. Verificouse que essas maiores distâncias foram obtidas entre os grupos dos genótipos resistentes e suscetíveis (Tabela 5).

Tabela 4. Agrupamento dos 51 genótipos de feijão-de-corda (Vigna unguiculata) pelo método de otimização de Tocher, baseado na dissimilaridade expressa pela distância de Mahalanobis.

\begin{tabular}{lcc}
\hline Grupo & Cultivares & Distâncias médias \\
\hline 1 & BRS Guariba, TVu 410, BRS Paraguaçu, TVu 36, TVu 408 P, Sempre Verde & 0,977 \\
2 & Inhunmã, Chumbinho, Vita 7, IT91K-118-2, CNCx 251-76E, Milagroso, CNCx 251-60E, Jatobá, Aparecido UFC, & 0,892 \\
& Burgandy Cowpea, Rouxinho-2, IT87D-611-3, IT82D - 60, AU94-418-07-01, CB - 3, Sete Semanas, CNCx 251-11E, & \\
& BRS Gurguéia, UCR-95-701, CB - 27, 7917-Dixie hee, ER-7, 58.185, Maranhão, IT93-10-93, Paulistinha, BRS Marataoã & 0,891 \\
3 & TVx 4662-07F, Frade Preto, MNC03-720-11, Lisão CE, Purple KNUCKIE Hull-55, BR 9- Longá, Pitiúba, MNC & 1,005 \\
4 & 03-720C-11, Manteiguinha & 1,573 \\
5 & MNC01-627D-65-1, TVu 1037, Setentão & 1,811 \\
6 & Rouxinho 1, MNC-00-553-D-81-2-3 & 0,000 \\
7 & IT 870-611-3, MNC-00-5190-1-1-5 & 0,000 \\
8 & BRS Rouxinol & Epace 10 \\
\hline
\end{tabular}

Tabela 5. Distâncias médias dentro e entre os oito grupos formados com os 51 genótipos de feijão-de-corda (Vigna unguiculata) avaliados.

\begin{tabular}{|c|c|c|c|c|c|c|c|c|}
\hline Grupo & 1 & 2 & 3 & 4 & 5 & 6 & 7 & 8 \\
\hline 1 & 0,977 & 39,933 & 32,421 & 6,871 & 39,842 & 22,394 & 20,886 & 4,370 \\
\hline 2 & - & 0,892 & 3,815 & 17,678 & 2,716 & 5,674 & 3,460 & 24,740 \\
\hline 3 & - & - & 0,891 & 10,936 & 8,013 & 4,476 & 3,735 & 20,911 \\
\hline 4 & - & - & - & 1,005 & 19,831 & 7,667 & 6,584 & 4,620 \\
\hline 5 & - & - & - & - & 1,573 & 10,192 & 4,292 & 27,108 \\
\hline 6 & - & - & - & - & - & 1,811 & 2,552 & 9,847 \\
\hline 7 & - & - & - & - & - & - & 0,000 & 11,255 \\
\hline 8 & - & - & - & - & - & - & - & 0,000 \\
\hline
\end{tabular}




\section{Conclusões}

1. Os cruzamentos entre os genótipos Setentão e BRS Guariba, TVu 410, BRS Paraguaçu, TVu 36, $\mathrm{TVu} 408 \mathrm{P}_{2}$ e entre Epace 10 e Sempre Verde, BRS Guariba e TVu 410 são os mais indicados para a obtenção de híbridos em programas de melhoramento para resistência ao pulgão-preto.

2. Os genótipos BRS Guariba, TVu 410, BRS Paraguaçu, TVu 36, Sempre Verde, TVu $408 \mathrm{P}_{2}$, Setentão e Epace 10 apresentam maior resistência natural ao pulgão-preto.

3. A associação da classificação de Mulamba \& Mock com o teste de Scott-Knott é eficaz em avaliar a divergência genética entre os genótipos, com resultado semelhante ao obtido pelo método de otimização de Tocher.

\section{Referências}

ABREU, A. de F.B.; RAMALHO, M.A.P.; FERREIRA D.F. Selection potential for seed yield from intra and inter-racial populations in common bean. Euphytica, v.108, p.121-127, 1999

CRUZ, C.D. Programa Genes: estatística experimental e matrizes. Viçosa: UFV, 2006. 285p.

CRUZ, C.D.; REGAZZI, A.J. Modelos biométricos aplicados ao melhoramento genético. Viçosa: UVF, 2001. 390p.

DIAS, F.T.C.; SILVA, A.P.M. da; BERTINI, C.H.C. de M. Genetic divergence in cowpea genotypes with upright growth and early cycle. Crop Breeding and Applied Biotechnology, v.9, p.253-259, 2009

HALL, A.E.; CISSE, N.; THIAW, S.; ELAWAD, H.O.A.; EHLERS, J.D.; ISMAIL, A.M.; FERY, R.L.; ROBERTS, P.A.; KITCH, L.W.; MURDOCK, L.L.; BOUKAR, O.; PHILLIPS, R.D.; MCWATTERS, K.H. Development of cowpea cultivars and germplasm by the Bean/Cowpea CRSP. Field Crops Research, v.82, p.103-134, 2003.

MORAES, J.G.L.; BLEICHER, E. Preferência do pulgão-preto, Aphis craccivora Koch, a diferentes genótipos de feijão-de-corda, Vigna unguiculata (L.) Walp. Ciência Rural, v.37, p.1554-1557, 2007.

MULAMBA, N.N.; MOCK, J.J. Improvement of yield potential of the method Eto Blanco maize (Zea mays L.) population by breeding for plant traits. Egyptian Journal of Genetics and Cytology, v.7, p.40-51, 1978.

OBOPILE, M. Economic threshold and injury levels for control of cowpea aphid, Aphis craccivora Linnaeus (Homoptera: Aphididae) on cowpea. African Plant Protection, v.12, p.111-115, 2006.

OBOPILE, M.; OSITILE, B. Life Table and population parameters of cowpea aphid, Aphis craccivora Koch (Homoptera: Aphididae) on five cowpea Vigna unguiculata (L. Walp.) varieties. Journal of Pest Science, v.83, p.9-14, 2010.

OFUYA, T.I. Control of the cowpea aphid, Aphis craccivora Koch (Homoptera: Aphididae), in cowpea, Vigna unguiculata (L.) Walp. Integrated Pest Management Reviews, v.2, p.199-207, 1997.

OLIVEIRA, F.J. de; ANUNCIAÇÃO FILHO, C.J. da; BASTOS, G.Q.; REIS, O.V. dos. Divergência genética entre cultivares de caupi. Pesquisa Agropecuária Brasileira, v.38, p.605-611, 2003.

PAINTER, R.H. Insect resistance in crop plants. $2^{\text {nd }}$ ed. Lawrence: The University Press of Kansas, 1968. 520p.

RAKHSHANI, E.; TALEBI, A.A.; KAVALLIERATOS, N.G.; REZWANI, A.; MANZARI, S.; TOMANOVIĆ, Ž. Parasitoid complex (Hymenoptera, Braconidae, Aphidiinae) of Aphis craccivora Koch (Hemiptera: Aphidoidea) in Iran. Journal of Pest Science, v.78, p.193-198, 2005.

RIBEIRO, N.D.; LONDERO, P.M.G.; HOFFMANN JUNIOR, L.; POERSCH, N.L.; CARGNELUTTI FILHO, A. Dissimilaridade genética para teor de proteína e fibra em grãos de feijão dos grupos preto e de cor. Revista Brasileira de Agrociência, v.11, p.167-173, 2005.

SCOTT, A.J.; KNOTT, M. A cluster analysis method for grouping means in the analysis of variance. Biometrics, v.30, p.507-512, 1974.

SILVA, J.F. da; BLEICHER, E. Resistência de genótipos de feijão-de-corda ao pulgão-preto. Pesquisa Agropecuária Brasileira, v.45, p.1089-1094, 2010.

SINGH, S.R. Cowpea cultivars resistant to insect pests in world germplasm collection. Tropical Grain Legume Bulletin, v.9, p.1-7, 1977.

SOUZA, J.R. de; FERREIRA, E.; CARGNELUTTI FILHO, A.; BOIÇA JÚNIOR, A.L.; CHAGAS, E.F. das; MONDEGO, J.M. Divergência genética de cultivares de arroz quanto à resistência a Tibraca limbativentris Stål(Hemiptera: Pentatomidae). Neotropical Entomology, v.38, p.671-676, 2009.

SUINAGA, F.A.; CASALI, V.W.D.; SILVA, D.J.H. da; PICANÇO, M.C. Dissimilaridade genética de fontes de resistência de Lycopersicon SPP. a Tuta absoluta (Meyrick, 1917) (Lepidoptera: Gelechidae). Revista Brasileira de Agrociência, v.9, p.371-376, 2003.

Recebido em 3 de janeiro de 2012 e aprovado em 26 de junho de 2012 